\title{
Publisher Correction: Anthropogenic impact on the atmospheric microbiome
}

Stephen D. J. Archer (1) and Stephen B. Pointing (D)

Correction to: Nature Microbiology https://doi.org/10.1038/s41564-019-0650-z, published online 28 January 2020.

In this Comment originally published, in Fig. 1b(iii), the label 'Fossil fuels' for the grey shape was missing. This has now been corrected.

Published online: 25 February 2020

https://doi.org/10.1038/s41564-020-0680-6

(C) Springer Nature Limited 2020 